\title{
CONVERSOS MUSULMANES EN \\ LA BERBERÍA CRISTIANA: \\ EL INFORTUNIO DE LA CRUZADA \\ PACÍFICA CONTRA EL ISLAM
}

\author{
POR
}

\author{
Beatriz Alonso Acero
}

Centro de Estudios Históricos, (CSIC), Madrid

\section{RESUMEN}

La labor evangelizadora respecto a los musulmanes realizada por la Iglesia cristiana en los enclaves conquistados por Castilla en Berbería en los años finales del siglo XV y primeros del XVI, cruzada pacifica contra el infiel, parte de unos presupuestos previos de éxito cuya falsedad se encargará de demostrar la propia realidad. Pronto se hace patente la dificultad de llevar a buen término esta obra misionera. No existe un proyecto previo bien definido y trazado, lo que no favorece que lleguen a estas latitudes más eclesiásticos y mejor preparados. Además, la precariedad que padecen los presidios cristianos a los que se trasladan las órdenes religiosas encargadas del adoctrinamiento de estos musulmanes, tanto esclavos como libres, perjudica aún más la adecuada realización de esta tarea.

\section{ARSTRACT}

The conversion of muslims that Christian church achieves in the cities conquered by Castilla in Barbary during the last years of $\mathrm{XV}^{\text {th }}$ century and the first years of $\mathrm{XVI}^{\text {th }}$ century, peaceful crusade against the infidel, starts on falses estimates of sucess. From the beginning is evident that there are many troubles in this activity, because of the inexistence of a previous plan of action. This damages the arrival of a main number of monks and, overcoat, monks who are better teached. The troubles are also brought about the shortage that endures the Christian presidios where the monks indoctrinate these muslims, slaves or frees. 
Las relaciones mantenidas entre Cristiandad e Islam en tierras de Berbería durante los siglos modernos han atraído la atención de un importante número de investigadores que, desde tiempo atrás, intentan deslindar las pautas que enmarcan las situaciones de colaboración y de enfrentamiento que se han dado entre ambas religiones a lo largo de ese período. En las últimas fechas, y de forma totalmente justa y necesaria, se ha atendido especialmente a la realidad de los cristianos que, trasladados por diversas circunstancias a aquellas latitudes, unos por propia voluntad, otros por la fuerza al haber perdido su libertad, abandonan su primigenia religión y abrazan la fe musulmana. Estos conversos en sentido amplio, tanto se trate de tornadizos como de renegados propiamente dichos, captan nuestro interés a causa de sus peripecias vitales, que les llevan a atravesar la frágil frontera que separa a la Cristiandad del Islam. Ellos saben que de igual forma en un futuro quizás no lejano podrán volver a atravesarla en sentido inverso, aunque es posible que el precio que tengan que pagar por ello sea demasiado elevado. En el presente estudio, queremos llevar a cabo una reflexión sobre la realidad de los «otros», la de los musulmanes que viviendo en tierras de Berbería, donde el Islam es la religión dominante, acaban entrando por voluntad o a la fuerza en los pocos, dispersos y enquistados enclaves que posee España allende el Estrecho de Gibraltar, El exiguo papel desempeñado por la Iglesia cristiana en estas latitudes es el principal responsable de los resultados conseguidos en los intentos de conversión de los musulmanes y, en esta perspectiva, la gran diferencia existente entre lo que se esperaba llevar a cabo en el norte de Africa y lo que realmente se llegó a hacer, es lo que explica que esta política de conversión de los musulmanes berberiscos pueda medirse en términos de fracaso y frustración.

\section{FUNDAMENTOS TEÓRICOS DE LA CONVERSIÓN DEL MUSULMÁN}

Para los españoles del siglo XVI, el musulmán, definido como seguidor y practicante del Islam es, en esencia, un infiel. Con esta descripción, lo que se intenta señalar es la categoría del musulmán como no seguidor de la ley de Cristo, de la misma forma que para el musulmán el infiel es el cristiano, por no seguir el Islam. Dado que el cristiano está plenamente convencido de que la ley de Cristo es la única verdadera, concluye que el musulmán sigue una doctrina falsa ${ }^{1}$, quedando implícita la superioridad con la que el cristiano contem-

1 «Los autores cristianos creen que después del Nuevo Testamento era imposible que Dios volviera a dictar una nueva doctrina, por lo que el Coran tenía que ser obligatoriamente falso. Los únicos pasajes verídicos son aquellos que Mahoma copio literalmente de la Biblias. (M. Á. DE BUNES IBARRA. La imagen de los musulmanes y del norte de Africa en la Esparia de los siglos XVI y XVII. Los caracteres de una hostilidad. Madrid, 1989, p. 214).

Hispaniz, del Mediterráneo al Atlántico Hispania Sacra 51 (1999) 
pla su religión con respecto al Islam. Bajo estos presupuestos, el cristiano justifica su oposición al Islam y su deber de combatir esta religión, recuperando para el cristianismo a los adeptos a esta falsa fe.

Para llevar a cabo esta sagrada misión, tal y como la concibe el cristiano del Quinientos, es posible utilizar dos vías, que no se excluyen entre sí. La primera consiste en la conquista para la Cristiandad, mediante la fuerza de las armas, de los territorios dominados por el Islam; sería la forma más perfecta y depurada de la tradicionalmente llamada «guerra justa contra el infiel». La segunda vía, de corte pacífico, implica incentivar la presencia de la Iglesia cristiana en los territorios donde la fe mayoritaria es la musulmana, intentando convencer a los infieles de la verdad del cristianismo y animándoles a la conversión a la ley de Cristo, tras un necesario período de adoctrinamiento. Esta vía suele aparecer en muchos casos unida a la anterior, de tal forma que, tras la conquista de un enclave musulmán, no tardan en acudir representantes de la Iglesia cristiana cuya misión fundamental será extender esta fe a los habitantes musulmanes de las tierras vecinas a la conquistada para la Cristiandad. Esto es precisamente lo que encontramos, de forma generalizada, en el norte de África, en cuya conquista se vuelca España desde los años finales del siglo XV y muy especialmente en la primera década del Quinientos.

Dejando a un lado las causas de esta penetración española en el norte de África por no ser objetivo prioritario de este estudio ${ }^{2}$, hay que señalar que la primera incursión de la Cristiandad en las tierras del otro lado del Estrecho una vez finalizada la Reconquista se hace empleando la vía más violenta. Terminada la guerra de Granada, con la toma de la capital del reino en enero de 1492, se plantea la necesidad de llevar el cristianismo a tierras de Berbería, pues no en vano desde aquellas latitudes había partido el empuje conquistador musulmán de la Península Ibérica en los albores del siglo VIII y nada impedía que en un futuro próximo se volviera a intentar alguna entrada de intenciones similares. Es en este punto donde se inserta el concepto del «ideal de cruzada», que define a la empresa española en el norte de África como un meritoriaje ineludible antes de alcanzar la ansiada meta, Jerusalén ${ }^{3}$. Aunque los españoles, absorbidos por la Reconquista peninsular, lleguen tarde a incorporarse a la vieja empresa de la cruzada hacia Jerusalén, causa de un dilatado complejo

2 Para un informe de estas causas, vid. M. Garcta-ARENAL, M. Á. DE Bunes IBARRA. Los españoles y el norte de África, siglos XV-XVII. Madrid, 1992, pp. 21-55.

3 Sobre el concepto de cruzada y su aplicacion al caso español, vid. entre otros, C. ERDMANN. The origin of the idea of crusade. New Jersey, 1977, M. VILLEY. La Croisade, essai sur la formation d'une thérie juridique. New York, 1980, P. ALPHANDÉRY. La Chretiénté et l'ideé de croisade. París, 1995. J. GoNi GAZTAMBIDE, Historia de la Bula de la Cnzzada en España, Vitoria, 1958, y G. REYNAUD. «La lutte chrétienne contre le pouvoir musulman en occident ou l'origine iberrique de la croisade d'Orients, Sharq-Al-Andalus, $\mathrm{n}^{\circ}$ 8, (1991), pp. 243-247.

Hispania, del Mediterraneo al Attantico Hispania Sacra 51 (1999) 
frente al resto de los europeos, en los albores de la Edad Moderna se darán todas las circunstancias propicias para que España pueda hacer realidad en alguna medida sus sueños de cruzada contra el infiel, más allá del territorio peninsular. En este sentido, recordemos que Europa se ve sacudida por un rebrote del interés hacia el ideal de cruzada durante el ŕltimo tercio del siglo XV y el primero del siglo XVI (1470-1530), momento justo en el que se realizan las conquistas castellanas en el norte de África ${ }^{4}$. El infiel habita unas tierras que, además de considerarse herencia de la provincia romana de la Béti$\mathrm{ca}^{5}$, han sido señaladas por todos los textos proféticos sobre la conquista de Tierra Santa desde el siglo XIII como ruta inexorable en el camino hacia Jerusalén ${ }^{6}$, siendo Jaime II de Aragón quien especialmente defendí en este período la idea de llegar a Jerusalén por Granada y el norte de África ${ }^{7}$. En la teoría, el deseo de reintegrar a la Cristiandad los Santos Lugares, que permanecían aún en poder del infiel, es lo que mueve a los Reyes Católicos a intentar la vía norteafricana como camino intermedio en la ruta hacia Oriente; en la práctica, «la toma de Jerusalén es una conquista mítica. Es la lucha contra los moros, conversos, ricos, malos clérigos la que tiene el prestigio de la lucha escatológica por la Ciudad Santa» ${ }^{8}$. Berbería, en una posición estratégica para el control de un Mediterráneo occidental donde las actividades comerciales y mercantiles aún mantienen cierta pujanza, así como para la defensa de las costas españolas e italianas frente al auge del corso y la piratería, se alza como bastión de conquista para una Península que acaba de estrenar la unión de sus reinos y que se lanza hacia el sur presa de un evidente ideal expansionista. Desde Roma se anima a esta aventura norteafricana encamada de forma principal por Castilla: las bulas pontificias de Alejandro VI ofrendan a la conquista de Berbería el apoyo religioso y económico necesario para iniciar tan magna empresa, si bien

4 «En estos momentos, las profecías mesiánicas sobre el aniquilamiento del Islam y la conquista de Jerusalén por Fernando el Católico tuvieron, al parecer, un eco importante en la población». (A. MILHOU, Colón y su mentalidad mesíánica en el ambiente franciscanista español. Valladolid, 1983, p. 323).

5 La Hispania Tingitana englobaba el territorio de la Mauritania, con capital en Tánger, y pasa a depender de la Bética romana desde el affo 69. Tras la caída del Imperio romano, esta Hispania Tingitana estará supeditada al reino hispano-godo hasta en que en el 554, la Mauritania, además de otros territorios sureuropeos, pasen a manos del emperador bizantino Justiniano. En el 615, Sisebuto reconquista Ceuta y parte de la Mauritania, a la que denomina Hispania Transfetana, que definitivamente caerfa en manos de los árabes y bereberes en el año 708. Vid. L. GALINDO Y VERA, Historia, vicisitudes y polttica tradicional de España respecto a sus posesiones en las costas de Africa..., Málaga, ed. Algazara, 1993 (reedición), pp. III-V.

6 Según estos textos, el esquema a seguir implicarí, en primer lugar, el aplastamiento del Islam espainol, para seguir con la conquista de Maruecos y terminar con la ruta hacia Jerusalén no por mar sino a través de Berbería, Túnez, Libia y Egipto. (A. MrLHOU, Colbn y su metalidad mesianica ..., pp. 354-355).

7 A. MiLhou, Colón y su mentalidad mesiánica .... p. 374.

8 A. MLlHOU, Colón y su mentalidad mesianica ..., p. 301.

Hispania, del Mediterráneo al Atlántico

Hispania Sacra 51 (1999) 
nunca verá cumplido su último sueño de alcanzar Jerusalén, que será conquistada por Selim I en 1516 y anexionada al vasto Imperio otomano.

Desde que en 1497 se conquiste Melilla hasta que en el verano de 1510 se produzca el «desastre de los Gelves» (Djerba), diferentes enclaves de la costa mediterránea norteafricana son incorporados a la Corona de Castilla: Cazaza y Mazalquivir son conquistadas en 1505, el Peñon de Vélez de la Gomera en 1508, Orán en 1509, el Peñón de Argel, Bugía y Trípoli en 1510. A cada uno de estos territorios, al poco tiempo de haberse producido la anexión, se desplaza la Iglesia cristiana, representada por integrantes de diferentes órdenes religiosas, que, además de encargarse de mantener la fe de los españoles que pasan a vivir en estas latitudes y de rescatar a los que quedan cautivos en enclaves musulmanes, se ocuparán de intentar extender la fe cristiana, combatiendo al Islam mediante la predicación. En principio, la mentalidad preexistente en la España del Quinientos, de la que se imbuyen estos religiosos y con la que acuden al norte de África, coincide en suponer que esta tarea de conversión del infiel no ha de ser en exceso dificultosa. No en vano, los españoles piensan que si el Islam encontro tantos adeptos en el Magreb tan poco tiempo a partir del inicio de las predicaciones de Mahoma, en los comienzos del siglo VII, se debió a la rudeza y necedad de los berberiscos, a la sencillez del Islam, cuyos preceptos se alejan de sacrificios y renuncias, y al empleo de las armas para su expansión, prometiendo el paraíso a quienes morran empuñándolas en defensa de tan noble causa ${ }^{9}$. Sin embargo, la realidad se iba a encargar de demostrar la falsedad de los presupuestos de viabilidad bajo los cuales se preparó la, supuestamente, inmediata conversión de los musulmanes habitantes en las proximidades de los enclaves recién conquistados para la Cristiandad en Berbería.

Desde el primer momento, el número de eclesiásticos que fue destinado a poner en práctica la labor de conversión de los infieles norteafricanos se alejó en gran medida de lo que hubiera sido deseable para encarar una empresa semejante con alguna garantía. Según señaló F. Braudel, buena parte de ellos mostraba su desinterés en ser enviado a tal misión al entender que acudir a estos enclaves del otro lado del Estrecho era algo así como aceptar un destierro inmerecido ${ }^{10}$. En este sentido, la labor de evangelización del musulmán en el norte de África acabó correspondiendo por lo general a órdenes que tenían en la predicación y en el rescate de cautivos sus méritos fundamentales, $\cdot y$ que estaban acostumbradas a vivir en condiciones económicas extremas, caso de los franciscanos y de los dominicos, órdenes mendicantes por excelencia, y de

9 M. Á. DE BUNES IBARRA. La imagen de los musulmanes ... , pp. 216-217.

10 F. BRAUDEL, «Les Espagnols et l'Afrique du Nord de 1492 à 1577», Revue Africaine, vol. 69 , (1928), p. 378. Vid. la reciente traducción del artículo al espafiol, en F, BRAUDEL. En torno al Mediterráneo. Barcelona, Paidós, 1996, p. 82. 
los mercedarios, orden que, de acuerdo con los principios que San Pedro Nolasco, San Raimundo de Peñafort y Jaime I -quienes establecieron su fundación en el año 1218-, se consagraría al rescate de aquellos cristianos que cayeran cautivos de los musulmanes. Junto a ellas, otras órdenes como la de los trinitarios -orden redentora especialmente activa en el norte de África en la primera mitad del siglo XVII- y la Compañía de Jesús, aparecen en diferentes ocasiones participando de las labores de conversión del infiel desde su base en los diversos enclaves de la Cristiandad en Berbería. Por el contrario, no advertimos la presencia, al menos de forma estable y continuada, de alguna orden militar en estos presidios españoles del otro lado del Estrecho, a pesar de que en su fundación aparece de forma muy relevante el voto especial de lucha contra el infiel, tanto a través del uso de las armas, función desempeñada por los caballeros de estas órdenes, como a través de la predicación, encargada a los sacerdotes. Lo cierto es que estas órdenes llegan ya muy debilitadas a estos comienzos del siglo XVI: politizadas algunas de ellas, otras envueltas en luchas internas en las que el tema de los maestrazgos tiene mucho que decir, y casi todas ya bastante desentendidas de lo que es propiamente la guerra contra el Islam. Por estas causas, era difícil que la Corona confiara en ellas y si bien en algunos de estos presidios se intentó en un primer momento que su gobierno y administración corriera a su cargo, como ocurrió en Orán, Bugía y Trípoli, lo cierto es que estas pretensiones nunca cuajaron en ningún resultado práctico ${ }^{11}$.

Junto a la escasez de eclesiásticos dedicados a esta labor de evangelización, el otro gran problema que se alza para llevar a cabo esta tarea con algunas posibilidades de éxito, radica en la preparación de aquellos que acuden a Berbería con el propósito de convertir a los musulmanes. En la mayoría de ellos es evidente el desconocimiento del medio al que van a ser trasladados, ignorancia que alcanza los límites más asombrosos en comparación con lo que hubiera sido mínimamente deseable. Los eclesiásticos que se desplazan a Berbería no

11 El propio cardenal Cisneros propuso a Fernando el Católico en 1512 lo acertado de situar en Orán a la Orden de Santiago, en Bugía a la de Alcántara y en Trípoli a la de Calatrava, pero la idea nunca pasó de ser tal (G. SÁNCHEZ DONCEL,, Presencia de España en Orán, (1509-1792). Toledo, 1991, p. 586). Es posible que la precaria situación en la que se desarrolló la vida religiosa, política y económica de estos presidios norteafricanos hubiera sido otra muy diferente de haberse llevado a cabo tal propuesta. Así lo indica, ya durante el reinado de Felipe IV, el anónimo autor de un memorial que, bajo el título MEDIO para defender las costas de África, assegurando las plaças que el Rey Nuestro Señor tiene en ellas, ilustrando las ordenes militares, de que su Magestad es Maestre y perpetuo Administrador, s.i., s.1., s.a (B(iblioteca) N(acional) de M(adrid) V.E. 13-21) insiste en esta cuestión por las beneficiosas consecuencias que ello traería consigo en lo relativo a la financiación de las plazas. Según este texto, a través de la presencia de las Ordenes Militares en los territorios norteafricanos de control español se podría aplicar para su financiación, entre otras cantidades, una porción de las medias agnatas de cada orden, asi como las pensiones de las encomiendas vacantes (cap. VIII, fols. $18 \mathrm{r} .-21 \mathrm{r}$.).

Hispania, del Mediterráneo al Atlántico

Hispania Sacra 51 (1999) 
sólo parten de una imagen errónea y distorsionada tanto del Corán como de su practicante, el musulmán, sino que ni siquiera alcanzan a conocer la lengua en la que se expresan los seguidores de Alá. En estas condiciones, poco era lo que se podía hacer en favor de su conversión. Si a ello unimos la precariedad de medios con la que realizan su tarea, remedo de la que vive buena parte de la población que pasa a habitar en estos presidios, en especial de sus guarniciones, nos encontraremos con una labor evangelizadora que choca una y otra vez con dificultades que se acaban convirtiendo en insalvables. Como consecuencia, las conversiones de musulmanes berberiscos debidas a la tarea de la Iglesia cristiana procedente de España acaban siendo muy escasas y casi siempre débiles, en lo que también hay que ver, una vez más, la condición de fronteras en la que se insertan estos enclaves, facilitando sobremanera el paso reiterado de una fe a otra a veces en lapsos de tiempo poco menos que increíbles.

\section{LA PRÁCTICA DE LA CONVERSIÓN: MUSULMANES ESCLAVOS Y MUSULMANES LIBRES EN EL CAMINO HACIA EL CRISTIANISMO}

El concepto de superioridad del cristianismo sobre el Islam, así como la forma a través de la cual España entra en Berbería, dando vía libre a la guerra justa contra el infiel, determinan las relaciones que en un futuro van a tener ambas religiones en ese mismo espacio magrebí. En este sentido, al considerarse al musulmán como enemigo a batir, se justifican los ataques contra él, que tanto pueden dar lugar a su muerte como a su captura. En este último caso aparecen los esclavos musulmanes, que en una medida tan importante pasaron a engrosar las listas de población de estos presidios cristianos. Pero es también la forma a partir de la cual España penetra en Berbería, ocupando sólo las costas y sin avanzar hacia el interior —ocupación restringida del espacio, según la terminología empleada por R. Ricard y F. Braudel ${ }^{12}$ - lo que obliga a que la relación de oposición y enemistad para con el musulmán con la que en un principio se cruza el Estrecho, acabe dando lugar a situaciones de estrecha colaboración. Esto ocurre desde el mimo momento en que los cristianos se dan cuenta de las dificultades que tienen para sobrevivir en esas latitudes por sí mismos, y comprenden que la única medida para salir adelante y perpetuar la presencia de la Corona española en Berbería consiste, precisamente, en obtener toda la ayuda posible de quienes han dominado ese espacio hasta entonces.

12 Sobre el concepto de ocupación restringida del espacio, vid. F. BRAUDEL, «Les espagnols et l'Afrique du Nord ...», y R. RICARD, «Les établissements européens en Afrique du Nord du XVt siècle au XVII' siècle et la politique d'occupation restreinte», Revue Africaine, vol. 79: (1936), pp. 687-688; ibidem, «Le probleme de l'occupation restreinte dans l'Afrique du Nord (XV-XVIII siecles), Annales. Economies, Societés, Civilisations, $\mathrm{n}^{\circ} 8$ : (1936), pp. 426-437. 
En ese momento se abrirá la posibilidad de que también los musulmanes libres puedan acceder a una plausible conversión a la ley de Cristo. En medio de todas estas circunstancias, el hecho de encontrarnos en territorios de frontera marcará de forma notoria estas conversiones, haciéndolas en muchas ocasiones menos firmes y definitivas de lo que la Iglesia cristiana hubiera deseado. Por este motivo, se hará necesario buscar una nueva vía que proteja a estos nuevos cristianos de la tentación de regresar al Islam que tan mayoritariamente está instalado en tierras magrebíes. La solución radicará en el envío a España de un notable porcentaje de estos recién convertidos o próximos a convertirse, pero la corta distancia que separa la Península Ibérica de las costas de Berbería tampoco supone ningún seguro para que estas conversiones de musulmanes al cristianismo sean verdaderamente firmes y duraderas.

Por lo que se refiere a los musulmanes esclavos, su llegada a las plazas cristianas suele venir precedida de una jomada o ataque contra alguna tribu de musulmanes que no colabora con los españoles; son los llamados moros de guerra, en oposición a los que sí cooperan, los moros de paz, siempre siguiendo la terminología de la época ${ }^{13}$. Capturados estos musulmanes por las guarniciones cristianas, serán llevados a los presidios, donde pasarán a ser subastados, al igual que los objetos materiales conseguidos por la fuerza durante el ataque. Sus compradores son las familias más adineradas de las plazas cristianas, que consiguen así una mano de obra prioritaria para el desempeño de las labores agrícolas y/o domésticas. En el presidio de Orán, donde se permite la presencia de un reducido núcleo judío, por los beneficios que de sus funciones se desprenden para la continuidad española en este enclave, van a ser las familias judías más poderosas las que encabecen por lo general estas compras de esclavos musulmanes, produciendo ello algunos problemas de cara a su conversión, como veremos más adelante. Si se trataba de esclavos de rescate, los preferidos por los cristianos por las ventajas económicas que se obtenían con su venta, para ellos seguía abierta la posibilidad del redención por parte de la tribu a la que pertenecían, circunstancia que beneficiará en tanta medida o más a las plazas cristianas como su compra por un amo particular. En efecto, si la subasta de los esclavos supone la entrada de sustanciosas cantidades de dinero que en algo pueden aliviar la penuria de las maltrechas arcas de estos presidios cristianos, el rescate por parte de la tribu supone, además de la lógica indemnización a su dueño cristiano, la entrega a las autoridades de estos enclaves de

13 Mientras que el término «cabalgadas hace referencia a una participación mayor de la caballería en el ataque, el término «rebato» especifica una actuación conjunta de infantería y caballería. «Jornada», por su parte, haría referencia a la duración de estas acometidas, ya que se intentaba que no se prolongaran durante más de una noche, para que la guarnición que participaba en ellas no dejara sin protección el presidio por mucho tiempo.

Hispania, del Mediterráneo al Atlántico

Hispania Sacra 51 (1999) 
grano - trigo y cebada, especialmente-, fundamental para el sustento de sus habitantes, amén de algún otro producto para la alimentación, como los dátiles, $o$ incluso bienes suntuarios, como las alfombras o los tapices, difíciles de conseguir desde dentro de las plazas dada la situación de aislamiento en la que quedan tras la conquista. Sin embargo, para algunos de estos esclavos la posibilidad de acceder a un futuro rescate queda anulada desde el primer momento, pues se les destinaba a salir de las plazas y ser enviados a España, donde continuarían manteniendo su condición de esclavos, lo que nos conduce al controvertido y aún no bien conocido tema de la Berbería cristiana como centro aprovisionador de esclavos para España durante los siglos modernos ${ }^{14}$.

Estos esclavos musulmanes que pasan a habitar en los presidios cristianos y que comprueban cómo la tribu a la que pertenecían se demora en acudir en su ayuda, acaban perdiendo poco a poco la esperanza en su rescate. Para ellos, la situación en la que quedan tras su captura, y posterior subasta y compra, es en absoluto halagiieña, indistintamente del trato que reciban por parte de sus amos. Han perdido su libertad y han quedado insertados en medio de una sociedad cristiana que justifica su condición de esclavos por ser seguidores de una falsa doctrina religiosa. En medio de esta situación, y comprobando cómo su rescate se prolonga indefinidamente sin que nadie venga a pagar por sacarles de la plaza cristiana en la que ahora viven y sirven, no son pocos los que deciden acercarse a la fe cristiana, sin que ello suponga un paso firme hacia su libertad. Según recogían las Partidas en sus títulos XXII (leyes 1, 3, 5, 6 y 7), y XXXI (ley 8), «si un esclavo de judío, moro o hereje, se convierte al cristianismo, quedaba libre sin pagar nada a su dueño. Pero los que eran esclavos de cristianos, aun recibiendo el bautismo quedaban sometidos a servidumbre» ${ }^{15}$. Ello no significaba que, en algún caso, el dueño pudiera decidir conceder la libertad a su esclavo como reconocimiento a su conversión. Por lo general, para que consiguieran su libertad, se seguían los mismos pasos que en la España de la época. La manumisión por parte del amo, bien por haber realizado el esclavo méritos suficientes a juicio de su amo, o bien por propia determinación de éste de cara a la redacción de su testamento, fue una de las más empleadas y

14 A modo de somera indicación, sobre esclavitud en relación con el área de nuestra investigacion vid: A. DOMfNGUEZ ORTIZ, «Esclavitud en Castilla durante la Edad Moderna», Estudios de $\boldsymbol{H}^{\circ}$ Social de Espafla, $\mathrm{n}^{\circ} 2,1952$, pp. 369-428, cuya consulta sigue siendo fundamental para este tema; W.D. PHILliPS, Historia de la esclavitud en Espafia. Madrid, Playor, 1990; J.L. CORTÉs LóPEZ, Los origenes de la esclavitud negra en España. Salamanca, 1986; ibidem, La esclavitud negra en la España peninsular del siglo XV. Salamanca, 1989; M. LOBO CABRERA, La esclavitud en las Canarias Orientales en el siglo XVI (negros, moros y moriscos). Gran Canaria, Ed. del Excmo. Cabildo Insular de Gran Canaria, 1982; V. GRAULLERA SANZ, La esclavitud en Valencia en los siglos XVI y XVII. Valencia, 1978

is Recogido por J. L. CORTÉs LOPEZ, La esclavitud negra ..., p. 142.

Hispania, del Mediterráneo al Atlántico Hispania Sacra 51 (1999) 
siempre vino favorecida por la previa conversión al cristianismo del esclavo. Este es el caso de Francisco de Salvatiesta, esclavo del amo del mismo nombre, lo que nos induce a pensar que se habría convertido a la ley de Cristo. En ese momento recibiría el nombre de su propietario, técnica común en la conversión de esclavos musulmanes en la España de la época. Su abandono del Islam favorece que este esclavo del capitán de Orán Francisco de Salvatiesta, reciba su libertad al cumplirse una de las cláusulas del testamento del que fue su amo ${ }^{16}$. Pero estas situaciones suponen la excepción frente a una norma que marca que conversión y libertad no van unidos; lo que sí ocurre con la conversión es que, en alguna medida, el esclavo que se aleja del Islam y abraza el cristianismo sí consigue mejorar su consideración social dentro de la plaza en la que habita, siempre que logre demostrar que su conversión ha sido sincera y no sólo una fórmula exterior de comportamiento. No se le puede conceder la libertad porque ello supondría la pérdida de una fuente de mano de obra gratuita con la que no se quiere dejar de contar, pero ello no impide que al esclavo que se ha convertido al cristianismo se le considere mejor que al que persevera en su errada y desviada fe.

La labor de adoctrinamiento de estos esclavos musulmanes que se acercan libremente al cristianismo es llevada a cabo por los miembros de las ordenes religiosas presentes en cada una de esta ciudades berberiscas, pero los propietarios de los esclavos, en el caso de que sean cristianos, también tienen un papel destacado de cara al final optimo del proceso de conversión. En realidad, tanto los representantes de la Iglesia como los amos de los esclavos empiezan su labor de cara a la conversión del esclavo mucho antes de que éste muestre deseos de aproximarse al cristianismo por propia voluntad. Y es que tanto los eclesiásticos como los amos tienen una ineludible obligación de acercar el cristianismo a los esclavos musulmanes que han pasado a ser población de estos enclaves. Unos y otros deben persuadirle de que sólo la ley de Cristo es verdadera y de que pueden abandonar sus errores de fe abrazando el cristianismo. Sus faltas y yerros, cometidos por haber mostrado fidelidad al Islam, quedarán borrados y podrán iniciar una nueva vida siguiendo la doctrina que lleva a la auténtica salvación. Con esta base, y si el esclavo muestra alguna predisposición hacia un futuro bautismo, se inicia el proceso de adoctrinamiento durante el cual el esclavo, en la propia casa de su amo y/o en los diversos conventos e iglesias de las órdenes religiosas, recibirá la instrucción adecuada en lo relativo a preceptos, obligaciones y devociones que la religión cristiana comporta. Es ahora cuando la falta de una preparación adecuada de los miembros de las órdenes religiosas se hace más patente, puesto que el musulmán está accediendo al conocimiento de una religión nueva y diferente,

16 A(rchivo) D(iocesano) de T(oledo). Libro de Bautismo, $\mathrm{n}^{\circ} 3$, fol. 111 v./21 mayo 1607. 
aunque dentro de los términos del estricto monoteísmo que también había marcado el Islam, y tendrá serias dificultades para acercarse a ella con la suficiente desenvoltura. No se trata ya sólo de que tuviera problemas para acceder a los textos sagrados, puesto que bien pudieran haberse trasladado a aquellos enclaves ejemplares de la Biblia traducidos al árabe, que de poco servirían si el esclavo no sabía leer, sino que el problema parte ya de la propia comunicación oral entre el eclesiástico y el esclavo, pues como bemos indicado el conocimiento de la lengua arábiga por parte de los españoles que pasaban a habitar en el norte de África era prácticamente nulo, y hasta los propios gobernadores y miembros de los cabildos se veían en la obligación de contar con intérpretes para poder entenderse con los musulmanes. Junto a esto, el escaso número de eclesiásticos que se trasladaban a estas latitudes para extender la fe cristiana entre los adeptos al Islam, provoca que los pocos que sí acuden se vean desbordados por las múltiples actividades a las que deben hacer frente y no puedan tener la constancia necesaria para conducir estos procesos de conversión en la forma en la que hubiera sido más oportuna.

$\mathrm{Si}$, a pesar de estas grandes precariedades, el esclavo acababa finalmente por abrazar el cristianismo, su futuro estará o bien dentro de la ciudad norteafricana donde se ha convertido, o bien en España. En el primer caso, dada su situación de cristianos, desempeñarán las mismas tareas que hasta entonces, pero se beneficiarán de una consideración social superior respecto a los esclavos no convertidos. Si con su conversión alcanzan la libertad, podrán llegar incluso a ejercer oficios exclusivamente destinados a la población cristiana y que tiendan a integrarles en la sociedad cristiana del presidio, participando al máximo de los ideales de defensa y protección frente a las incursiones musulmanas. Así, no será extraño que entren a formar parte de las guarniciones que vigilan estas plazas, tomando el nombre mogataces, aunque en sentido estricto el mogataz no ha de estar necesariamente bautizado ${ }^{17}$. Ahora bien, el hecho de vivir en una sociedad de frontera y las dificultades para sobrevivir en estos enclaves hicieron que en ocasiones estos esclavos ya convertidos decidieran salir de estas plazas y volver a integrarse en la cultura musulmana de la que procedían. Si su peripecia vital les lleva toparse con la Inquisición, intentarán demostrar que siempre estuvo presente en ellos el deseo de abrazar de nuevo el cristianismo, evitando así castigos mayores por parte del Santo Oficio. Juan Sánchez, berberisco esclavo de Gaspar Sánchez, vecino de Orán, declara haber

17 El término de mogataz «en su primera acepción remite al moro que, bautizado o no, servía como espía, guía o auxiliar en las tropas españolas de ciertos presidios africanos. En la segunda acepción, se aplica por extensión al moro de paz en la vecindad de ciertos presidios africanos que concertaba, a cambio de su defensa, convenios de coexistencia con las gentes cristianas de los presidios». (F. MAílo SALGADO, «Breves notas sobre la historia y el significado de la padabra «almogataz», Studia Zamorensia, $\mathrm{n}^{\mathrm{a}}$ 5, (1984), p. 480. 
sido capturado con doce años y llevado a este presidio «y que despues que estubo alli seys años pareçiendole bien la ley de los christianos y haviendo aprendido las quatro oraçiones se bautiço y volvio christiano y que al cavo de tres años, a persuaçion y ruegos de su madre y padrastro que heran moros de paz y entraban y salian quando querian en Oran se avia ydo a mostagan con intento de ser moro", más arrepentido volvió a Orán y a su fe cristiana ${ }^{18}$. Si, por el contrario, el recién convertido es enviado a España, se alejará el peligro de que se reinserte en la doctrina musulmana, aunque no del todo, pues en España sigue habiendo moriscos al menos hasta 1614 , buena parte de los cuales aún siguen siendo fieles al Islam. Con respecto a estos enviados a España aparecerán otros problemas. Su traslado era motivo de graves preocupaciones para las autoridades de las plazas norteafricanas, que debían vigilar por la seguridad de un viaje que, además, no estaba claro con que dinero se podía costear. Su adecuada integración en la sociedad cristiana de la Península Ibérica competía al gobierno español, que debía hacer todo lo posible para que el recién convertido no acabara volviendo al Magreb para retomar su antigua fe musulmana.

Entre estos esclavos musulmanes que abrazaban el cristianismo, había un importante sector integrado por personas de raza negra, que llegan a estos presidios también a partir de las razzias que los cristianos organizan contra las tribus de moros del entorno. En efecto, siguiendo las palabras de Diego Suárez Montañés, soldado asturiano que sirvió durante cerca de treinta años en el presidio de Orán, estos negros procedían de los reinos de Fez, Marruecos y Etiopía, territorios en los que el Islam estaba suficientemente expandido y asentado, aunque las religiones politeístas y animistas también tendrían un papel destacado'. En estas latitudes, estos negros han sido comprados por los moros de guerra, quienes los emplean como esclavos y como mercancía, de tal forma que los españoles, conociendo su valía económica, no dudan en estimarlos como objeto de captura preferente cuando llevan a cabo las cabalgadas contra estas tribus enemigas. Por otro lado, también entran negros en los presi-

18 A(rchivo) H(istórico) N(acional). Inquisición. Leg. 2022 / 32, fol. 17 r.-v. Relación de causas presentadas ante el Santo Oficio de Murcia. Reconciliado.

19 D. SUÁREZ MONTANÉs, Historia del Maestre úttimo que fue de Montesa y de su hermano Don Felipe de Borja, la manera de cómo goberno Orán y Mazalquivir ..., siendo alli capitanes generales. Madrid, ed. de Guillén de Robles, Sociedad de Bibliofilos Españoles, 1889, parte I, cap. III, p. 45, e ibidem, Avisos importantes para la Magestad de del Rey Nuestro Señor, acerca de algunos peligros y otras cosas a que se deve acudir con tiempo, en las plaças de Oran y Marçaelquivir, en sus reparos, para la seguridad y sosiego de los Reynos de España, y aprovechamiento de la hazienda y patrimonio Real, que por aquella parte se sigue y podra mas seguir en daño o veneficio, en no acudir o acudir con tiempo a ellos. Todo averiguado, entendido y ordenado por ..., asturiano, soldado antiguo y platico en aquellas plaças y Reynos, de treynta aftos de milicia en ellos. s.1., s.a. [1608], R(eal) A(cademia) de la H(istoria). $9 / 7161, n^{0} 5$, fol. 65 r. Ambos textos están siendo editados en el Centro de Estudios Históricos (CSIC) bajo la đirección del Dr. M. A. de Bunes Ibarra.

Hispania, del Mediterráneo al Atlántico

Hispania Sacra 51 (1999) 
dios cristianos sirviendo de moneda de cambio para efectuar los rescates de esclavos musulmanes de raza blanca que se hallan cautivos en las plazas cristianas. Estas dos formas de acceso serían las más habituales en aquellos enclaves en los que no existieran fluidas relaciones con tribus de moros de paz del entomo. En aquellas otras plazas en las que estas relaciones eran más estables y continuadas, como ocurre sobre todo en Orán, la forma más habitual de que los esclavos musulmanes negros entraran en el presidio cristiano fue a través del comercio, dado que estos moros de paz no dudaban en ofrecer a sus esclavos negros como parte de sus mercancías, junto a objetos como la cera y los dátiles. Estos esclavos negros se convierten en objetivo de compra preferente por parte de los mercaderes cristianos, observándose una progresiva inclinación hacia la mano de obra esclava negra sobre la blanca, en lo que mucho tiene que ver la facilidad que los primeros presentaban para su adoctrinamiento y conversión. Por medio de la compra de eștos esclavos negros, las posibilidades de acrecentar las almas seguidoras de la fe cristiana aumentaban poderosamente, pues estas personas aceptaban sin demasiadas negativas la labor de instrucción en la doctrina de Cristo que llevarían a cabo sobre ellas los esclesiásticos desplazados a las tierras magrebíes. El cabildo de Orán afirma en 1599 que, «(..) seria muy en deserviçio de dios nuestro señor el dexar de traer los dichos negros a esta çiudad los moros respecto de que se convierten a nuestra santa fee catolica en cada un año por esta çiudad solo mas de doçientos de los dichos negros que no teniendo espediente por aqui por falta de dinero acudiran a llevarlos a argel Tremeçen y otros lugares de moros y turcos infieles a venderlos» ${ }^{20}$.

Bien es cierto que de todos estos esclavos musulmanes negros que entraban en los enclaves cristianos solo una parte permanecían en ellos, mientras que los demás salían hacia España, demandante de mano de obra esclava de color. Al igual que ocurre con los esclavos blancos, Berbería se consolida, también en este caso, como enclave por excelencia de la exportación de esclavos negros a España y de aquí a buena parte de Europa y América. Si bien el momento de máximo auge en el envío de esta mano de obra esclava negra a la Península estaría en las últimas décadas del siglo XV y en la primera mitad del XVI, aún a mediados del Seiscientos sigue ejerciendo un papel destacado, como consecuencia de la abundancia en el número de estos esclavos que pueden ser conseguidos a buenos precios en el interior del continente africano.

Para todos estos musulmanes de raza negra que entraban en las plazas cristianas de una $u$ otra forma, la Iglesia llevo a cabo su correspondiente labor de catequización y adoctrinamiento, que aun padeciendo todas las precariedades y

20 A(rchivo) G(eneral) de S(imancas). G(uerra) A(ntigua). Leg. 542, s.f. / 20 abril 1599. Carta del cabildo de Orán al Consejo de Guerra. 
limitaciones reseñadas para el caso de los esclavos musulmanes blancos, consiguió mayores frutos. En esta labor también ejercieron un papel fundamental los amos de estos esclavos, si bien aunque se bautizaran, seguirían -como ocurría con los esclavos musulmanes blancos-dependiendo de su condición de siervos. Así le ocurre en Orán a Juan, «esclavo negro de juan garcia de almodovar de poco mas o menos veinte años de edad» ${ }^{21}$, que se bautiza en 1604, pero del que no consta que pase de la situación de esclavo a la de libre por motivo de su conversión, aunque también encontramos, para la misma ciudad norteafricana, ejemplos de negros que se bautizan una vez conseguida su libertad a través del tradicional sistema de la manumisión, como ocurre con Ana, «negra libre que hera esclaba del alferez alonso de angulo y es libre de hedad de deçiocho años poco mas o menos» ${ }^{22}$.

Por lo que se refiere a la conversión de los musulmanes libres, parece haber existido un mecanismo de actuación establecido en mayor o menor medida, al menos en algunas plazas cristianas de Berbería durante las primeras décadas del siglo XVI. De acuerdo con este método, los adoctrinamientos de quienes voluntariamente se allegan a estas plazas con el objetivo de abrazar el cristianismo se realizan en estos mismos presidios, y sólo una vez recibido el bautismo podrán salir del norte de África. Se trata de una medida que pretende que los que acuden a estos presidios no lo hagan como una forma de huir hacia España, buscando un futuro más alentador al otro lado del Estrecho que la vida que han llevado hasta entonces en Berbería. Por otro lado, con esta disposición se busca que las conversiones sean definitivas y que no exista el peligro de, una vez en España, dudar del proceso de conversión y no alcanzar finalmente el bautismo. Se intenta que, ya en España, el nuevo cristiano se integre en una sociedad de cristianos, donde no surja la tentación de volver a la antigua fe por el trato cercano con sus anteriores hermanos de religión, ni el riesgo de intentar ser recuperado para el mundo musulmán por familiares y amigos. Sin embargo, éste va a ser un método de actuación que tan sólo podrá ponerse en práctica durante algunos años tras las conquistas llevadas a cabo por la Cristiandad en el norte de África. En cuanto se compruebe la cortedad del número de eclesiásticos que podían ocuparse de estas tareas evangelizadoras, su deficiente preparación y las precarias condiciones materiales en medio de las cuales han de llevar a cabo su labor, se estimará más conveniente llevar a España a estos conversos potenciales desde el mismo momento en que llegan a las plazas pidiendo ser adoctrinados en la ley de Cristo. Así había venido ocurriendo en el Peñón de Vélez de la Gomera a raíz de su segunda ocupación española en 1564, tras haber permanecido en manos musulmanas desde 1522.

21 ADT. Libro de Bautismos, $\mathrm{n}^{\circ}$ 3, fol. 24 r. $/ 3$ abril 1604

22 ADT. Libro de Bautismos, $n^{\circ}$ 1, fol. 22 r. / 18 abril 1590. 
A estos conversos musulmanes del Peñón se les embarcaba lo antes posible para Málaga, dándoles una ración ordinaria y una libranza de seis ducados para los proveedores de aquella ciudad portuaria.

Pero no sólo era por causa de la precariedad con la que la Iglesia cristiana desarrollaba su labor en los presidios cristianos por lo que se prefería enviar a estos conversos potenciales a España y que allí se convirtieran. Durante el tiempo que duraba su proceso de conversión a través de las instrucciones que recibía en el interior de algún convento o monasterio de los existentes en cada presidio, se estimaba que la presencia de estos musulmanes libres podía significar un obstáculo para la labor defensiva que es necesaria ejercer sobre estas plazas. Quien más y quien menos pensaba en qué ocurriría si el musulmán al final no se convertía y, reinsertándose en el mundo árabe del que procedía, optaba por contar los secretos defensivos de estos presidios a sus congéneres, $\mathrm{e}$ incluso se consideraba la posibilidad de que estos musulmanes libres fueran en realidad espías al servicio de Argel o de Estambul. Dado que, además, no fueron pocas las situaciones en las que los cristianos trataron vejatoriamente a estos musulmanes que iban a abrazar o ya habían abrazado la ley de Cristo, dudando de la verdad de su conversión, y si tenemos en cuenta también que algunos de estos conversos quedaban en los presidios sin medios para subsistir, lo más conveniente parecía enviarles desde un principio a España y que allí fueran adoctrinados y alcanzaran el definitivo bautismo.

Para aquellos con los que, a pesar de lo que era preferible, no se seguía este procedimiento, ni el período de estancia en las plazas - en el caso de que fueran allí adoctrinados y luego bautizados en España-, ni la propia travesía hacia la Península - se realizara ésta antes o después del bautismo- eran situaciones fáciles para las autoridades religiosas y seculares de estos presidios. Y es que desde que entraba en él todo le era costeado al futuro converso: alojamiento, manutención, pasaje a España, lo que suponía un conjunto de gastos a los que en muchos casos la Iglesia desplazada a estos territorios no podía hacer frente, por lo que solía ser la Corona quien los pagaba. En algunas ciudades, como en Orán, ante esta gran precariedad de la Iglesia, y con una Corona que aun dando algún dinero no se siente obligada por ninguna ley a costear estos gastos, llegan a ser algunos gobernadores los que se encarguen de todas estas cargas económicas. Así le ocurre a D. Felipe Ramírez de Arellano, conde de Aguilar, quien en 1612 refiere cómo es él quien, desde que el futuro converso entra en el convento hasta que se embarca para ser bautizado en España, le proporciona alimento y vestido, pagándoles luego también la travesía marítima ${ }^{23}$. El problema será cuando ya ni las propias autoridades seculares de

23 AGS. GA. Leg. 773, s.f. / 20 abril 1612. Carta del Conde de Aguilar en respuesta a una orden de Felipe III pidiendo le informe sobre qué se hace con los musulmanes que van a Orán a bautizarse. 
estas plazas puedan hacer frente a estos gastos. Y esto no tarda en ocurrir, conforme se incrementa la penuria en la que viven los presidios norteafricanos casi desde su conquista, claro remedo de los problemas que tienen las arcas de la Monarquía según avanza el siglo XVI, perpetuados en la primera mitad del XVII. En Orán esta situación se alcanza en 1629, momento en el que también estalla la polémica sobre quién debía costear los gastos derivados de la catequización de los musulmanes. El problema de fondo no es, en realidad, sino la inexistencia de una formulación clara al respecto. Ante la falta de una disposición legal, los gobernadores de los presidios tienden a refugiarse en los derechos de la Corona, exenta de la obligación de estos pagos, no elevados en exceso, pero siempre gravosos para una hacienda en estado precario. Por su parte, la Iglesia, aunque done algunas remesas para estos menesteres, también se declara libre de esta obligación que a su juicio recae en la Corona, aunque sólo sea por el peso de la costumbre. En la fecha señalada, la Iglesia señala los inconvenientes que se desprenden de que el gobernador, ahora ya D. Francisco de Andia Irarrázabal, se niegue a seguir costeando con dinero de la real $\mathrm{Ha}$ cienda estos gastos:

«y que para los renegados que adelante vinieren a las plaças de oram para el mesmo fin le diessemos orden como sustentarlos en el entretanto que se remitian a este santo officio porque el capitan general de oram que lo solia haçer se escussaba con que S.M. no avia de pagar semejantes gastos de lo qual nos a parecido dar quenta a V.A. por ser cossa nueba lo que diçe el dicho capitan general y dello se siguen dos yncombinientes considerables el mas prinçipal, el ympedirsse a el pareçer por este camino la redemcion o combersion de los dichos renegados pues biendo la mala acogida que se les haçe em alimentarlos en el entretanto que se despacha para el santo officio no bendran a goçar del edicto de gracia como lo an hecho asta aqui, el otro que si el santo officio ubiesse de acudir a dar alimentos a los dichos renegados voluntarios le seria de mucho gasto y penosso el dar dineros en oram. Para ello ademas de otros yncombinientes que çerca de la distribuçion y forma destos alimentos se siguen sobre que V.A. se serbira de prober del remedio combeniente dando orden a el capitan general que oy es de dicha oram no haga nobedades esto sino se guarde la costumbre (...) $\star^{24}$.

Las adversas circunstancias que rodean la adecuada realización de las tareas evangelizadoras de la Iglesia cristiana en Berbería acaban por hipotecar el

24 AHN. Inq. Leg. 2087, s.f. / 20 febrero 1629. Carta de Juan Ortiz de Zarate y del licenciado Briones Ayala, del Santo Oficio de Murcia, encargado de velar por la ortodoxia de la fe cristiana en Orán. La respuesta a la consulta de los inquisidores demuestra hasta que la Iglesia estaba totalmente resuelta a no ceder en esta cuestión, al insistir en las mistmas soluciones: «que el tribunal general ordene a los ministros que tienen en oran den un recado al governador general o capitan de oran sinificandole las costumbres que en esto a avido y que podra ocupar a los renegados que se binieren a reducir a nuestra santa fee catholica en las cosas que se ofrecieren al servicio de S.M.».

Hispania, del Mediterráneo al Atlántico

Hispania Sacra 51 (1999) 
aliento con el que los pocos religiosos allí presentes encaraban dicha labor. Esto era aún más evidente cada vez que la realidad demostraba que en muchas ocasiones la única razón que movía a estos musulmanes libres a abrazar por voluntad propia la fe cristiana era el interés por abandonar - temporal o definitivamente- un modo de vida y subsistencia en el que la precariedad era también denominador común. El moro Amete, declarando su deseo de ser cristiano, es llevado al monasterio de San Francisco de Orán para su adoctrinamiento, mas, llegado el momento de su bautismo finge no desear hacerlo a los ojos de sus hermanos de religión en Berbería sino en España. Enviado a la Península, unos meses después el conde tiene noticia de que era un farsante, y que en Murcia donde se halla se dedica a embustes e insolencias, demostrándose la falsedad de su conversion ${ }^{25}$. De otros musulmanes conversos enviados a España por el conde de Aguilar se tendrá noticia pocos meses después de que están regresando a Berbería a través de Francia ${ }^{26}$. Cuando en Berbería se sufran períodos de especial penuria, con malas cosechas, es cuando un mayor número de musulmanes se acercarán a la ciudad de Orán con intención de convertirse. Pero aun siendo Iglesia y Corona conscientes de esta situación, estiman que el fin que se alcanza justifica la poca sinceridad del medio que se emplea para acceder a él. En este sentido, incluso, no es difícil encontrar posturas providencialistas en relación con este asunto, según las cuales habria sido Dios quien habría empleado este medio de provocar cosechas escasas para incitar a los musulmanes a acercarse al cristianismo:

«Sienpre que ay esterilidad en berberia son muchos los moros que bienen a bolversse cristianos y aunque el primer motibo sea por remediar su neçesidad y no morir de hambre no se pueden dejar de admitir particularmente considerando que puede tomar este medio dios para que se reduzgan a nuestra santa fe no obstante que a los prinçipios no entren con berdadero ferbor ysntruydos pueden ser como deben ser buenos cristianos, este año son mas de sesenta los que se an catequiçado y entre ellos un judio de Tremezen" ${ }^{27}$.

25 AGS. GA. Leg. 758 , s.f. / 25 febrero 1611 y AGS. GA. Leg. 760 , s.f. / 10 noviembre 1611. Cartas de D. Felipe Ramírez de Arellano. Este moro, dice ser hijo de Muley Naçar, descendiente del rey de $\mathrm{Fez}$, algo que luego se demuestra totalmente falso. Por sus embustes y falacias para conseguir pasar a España, será perseguido por la justicia y hecho preso; en junio de 1613 se remite al Consejo de Guerra un proceso contra él, en el que el conde de Aguilar declara cómo Amete -durante su estancia en Orán- había Ilegado a animar «a los soldados (a) que se fuesen con el descolgandose por las murallas». (AGS. GA. Leg. 786, s.f. / 25 junio 1613. Carta del conde de Aguilar).

26 AGS. GA. Leg. 797, s.f. / 28 septiembre 1614. Carta de D. Felipe Ramírez de Arellano. El gobernador desea que estos renegados caigan en sus manos, y dicta ordenes para que los moros de paz no los acojan, so pena de ser considerados de guerra. Al mismo tiempo, pide nuevas instrucciones al rey para saber cómo ha de actuar respecto a los últimos convertidos que aún están en las plazas, para que no se repita la misma situación que con los que salieron de Orán meses atrás.

27 AGS. GA. Leg. 786, s.f. / 17 septiembre 1613. Carta de D. Felipe Ramírez de Arellano. El gobemador suplica se le de alguna limosna para acoger a tantos conversos, pues aunque él ha acudido 
Tanto las autoridades religiosas como las seculares son conscientes de la relación existente entre penuria y conversión, pues no en vano conocen cómo está ocurriendo lo mismo, aunque a la inversa, entre la gente de guerra de estos presidios, que harta de soportar tantas dificultades y privaciones, decide desertar y emprender la huida hacia tierra musulmana donde abandonarán el cristianismo convirtiéndose al Islam. Pero también estiman que no es fácil conocer la realidad que anida en los corazones de quienes se acercan a los enclaves cristianos con intención de abrazar la fe cristiana y que lo único que se puede hacer es, para descubrit si hay alguien que sólo busca acabar con el hambre que padece, disponer que antes de enviarlos a los monasterios para catequizarse se les dé un plazo para recuperarse de sus insatisfechas necesidades vitales. Así hizo el conde de Aguilar en Orán, permitiendo a estos conversos potenciales que estuvieran varios días en su casa, donde «se les requiere los requisitos que a de tener la conbersion y se les da libertad para bolbersse a su tierra si ya despues de aber comido se arrepienten del buen proposito y algunos lo an echo" ${ }^{28}$.

En aquellos casos en los que el bautismo no se alcanza en los presidios norteafricanos también habrá que tener precaución para que la labor catequizadora continúe de forma adecuada en España, donde han de enviarse estos catecúmenos. En aquellos períodos en que la escasez en Berbería hace que lleguen a las plazas cristianas un mayor número de musulmanes, desbordando las posibilidades de conseguir una buena acogida por parte de una población religiosa tan escasa, se hará más frecuente el envío de estos catecúmenos a España. Pero su acogida en tierras de la Cristiandad europea no será siempre la más oportuna para incentivar a un mayor número de conversiones por parte de estos musulmanes norteafricanos. En los años 1613-1614, períodos de cosechas muy poco fértiles en Berbería, que dan lugar a graves hambrunas, se llega a recriminar los masivos envíos de musulmanes a una España que vive aún los episodios finales de la expulsión de los moriscos, iniciada en 1609. En Orán, el conde de Aguilar explica cómo envió a España tres centenares de conversos en 1613-14, debido al «ynconbiniente en el catequiçarse aqui assi por la poca capacidad de los conbentos como por los pocos relijiossos que pueden asistir a ellos como por el trato que tienen los demas moros lo cual es caussa de hu-

\footnotetext{
con lo que ha podido, no es suficiente. Él mismo informa de que el cardenal de Toledo solía acudir antes en alguna medida a este remedio y ahora no lo hace, nuevo ejemplo de las rencillas que siempre existieron entre Corona e Iglesia en esta cuestion. El Consejo le responde que «asi como vayan [...] los vayan enbiando luego a españa para que aca se catequizen teniendo consideraçion a que aunque alla tanta neçesidad aora se juzga que deven de venir mas por bibir que por devoçion pero que si en tales moviere los vaya enviando en la forma referida».

28 AGS. GA. Leg. 797, s.f. / 8 marzo 1614. Carta de D. Felipe Ramírez de Arellano, conde de Aguilar.
}

Hispania, del Mediterráneo al Atlántico Hispania Sacra 51 (1999) 
yrsse algunos de los moros de los monesterios, por persuaçiones de sus parientes dejando el buen proposito de ser cristianos» ${ }^{29}$. Sin embargo, la respuesta a su carta hace ver hasta qué punto está presente en el gobierno de la Monarquía el espíritu que ha protagonizado la expulsión de los moriscos: «que se escriva al conde que quando se le mando que embiase a españa a estos que se bienen a reduçir a la fee fue creyendo que solo vendrian muy pocos como se solia hacer por lo pasado pero que viniendo tanto numero les a hecho ver que lo hacen por no morir de ambre siendo el año tan esteril y que assi debe sobreseher el cumplimiento de la orden mayormente en tiempo que se han expelido de España los moriscos muchos de los quales ha muchos años que viven en estos Reynos». Con ello, el ideal de expansión de la fe cristiana que había animado a la conquista del norte de África en los años finales del siglo XV y comienzos del XVI, tendía a quedar ahogado por las nuevas circunstancias que atravesaba la Monarquía, si bien en muchos casos se demostraba la escasa autenticidad de estas conversiones, muy condicionadas por la lucha por la supervivencia.

Para finalizar nuestro estudio, creemos oportuno dedicar algunas líneas a la situación concreta que se genera cuando entran en contacto en el norte de África el islamismo, el judaísmo y el cristianismo, después de tanto tiempo de haber compartido el suelo ibérico. Desde los parámetros de conversión que estamos manejando en el presente estudio y tomando como marco de referencia la ciudad de Orán, que como más arriba señalábamos fue uno de los presidios norteafricanos que, junto con Ceuta, Larache, Tánger y Mazagán, permitieron población judía en sus interior, apuntamos algunos datos en referencia a estos judíos en dos vertientes principales. Por un lado, nos interesa su faceta como amos de esclavos musulmanes, con lo que conseguiremos completar el panorama de la Iglesia cristiana en su particular cruzada contra el Islam en tierras de Berbería. Por otro, y aunque con el riesgo de excedernos en el estudio específico de las conversiones de los fieles al Islam, creemos interesante analizar la postura del judío que vive en presidios cristianos como converso en potencia, para así completar la visión sobre la labor catequizadora llevada a cabo en el otro lado del Estrecho por la Iglesia cristiana.

En cuanto al judío como propietario de esclavos musulmanes, recordemos que, en buena medida, son aquellas familias judías que disponen de más rentas las que con más frecuencia compran estos esclavos en las subastas realizadas tras una jornada contra moros de guerra. También pueden llegar a poseer esclavos musulmanes siendo obsequiados con ellos después de haber participado como guías en estas empresas de ataque contra los moros hostiles del entorno, o pueden haber servido de recompensa a estos hebreos ante cualquier servicio

29 AGS. GA. Leg. 797, s.f. / 8 marzo 1614. Carta de D. Felipe Ranúrez de Arellano, conde de Aguilar. 
dispensado para el buen gobiemo y administración de los presidios. Ahora bien, a diferencia de lo que ocurría en el caso de los amos cristianos, las Partidas establecían que un esclavo comprado por un judío alcanzaba innegablemente su libertad cuando se convertía al cristianismo. Y es ahí donde empezarán las disensiones tanto por parte de los amos hebreos como por la de sus esclavos musulmanes y también por la de los cristianos, pues no en vano son las autoridades de cada uno de los presidios las que deben arbitrar en los conflictos que se suceden por esta causa. Los judíos van a ser acusados por los habitantes cristianos de estos presidios de imposibilitar a sus esclavos musulmanes de intentar siquiera acercarse a los preceptos de la fe cristiana, y de no conceder la libertad a aquellos que al fin se convierten, con el objeto de no perder tan fecunda mano de obra. Estas acusaciones sobre los judíos en su faceta de amos de esclavos musulmanes pueden ser ciertas o no, pero en ellas siempre hemos de ver la hostilidad con la que muchos cristianos contemplan la presencia judía en las ciudades norteafricanas en las que ellos mismos viven. La documentación consultada al respecto muestra cómo buena parte de los esclavos musulmanes de judíos realizan con gran prontitud su conversión a la fe cristiana, aunque sólo sea con el objetivo - nunca confesado- de alcanzar la libertad. En este sentido, es muy revelador el testimonio de D. Martín de Córdoba, que tras haber desempeñado el gobierno de Orán entre 1575-1580 y 1581-1585, afirma en 1598, ya desde España, que

«antes los moros que compran los judios con muy poca o ninguna persuasion se vuelven cristianos por que en siendolos quedan libres lo que no hazen los que se compran los vezinos y naturales los quales siempre procuran comprar moro que sea de rescate y por no perderle jamas tratan de reducirle a que sea cristiano y el moro tampoco se inclina a ello visto que aunque lo sea se ha de quedar siempre por esclavo perpetuo de servicio ${ }^{30}$.

con lo que estaría apuntando de lleno a la diferencia fundamental existente en relación con la conversión del musulmán al cristianismo según se trate de un esclavo propiedad de un cristiano o de un judío, diferencia que favorecería al amo judío, al menos en cuanto a resultados prácticos vistos desde la perspectiva de la Iglesia cristiana. Este testimonio, además, supondría una crítica

30 AGS. GA. Leg. 518, s.f. / 5 abril 1598. Carta de D. Martín de Córdoba. Este testimonio se enmarca en un período especialmente convulso para los judíos de Orán, que después de haber visto mermada la cifra de sus componentes en 1591, tras ser expulsados los judíos forasteros, observan como se promulga un nuevo bando de expulsión en 1598 que en esta ocasión no tendrá efectos prácticos, al derogarse en 1599. Lo cierto es que una de las claúsulas del bando de 1598 exponía la prohibición a los judíos de comprar esclavos, siendo éstos declarados libres e imposibilitados de ser comprados por los cristianos después, bajo pena de 500 ducados, empleados para la reparación de la muralla de Orán.

Hispania, del Mediterráneo al Atlántico Hispania Sacra 51 (1999) 
directa al sistema a través del cual los cristianos toman en sus manos la evangelización de sus esclavos: la falta de resultados favorables tanto para el amo como para el esclavo, aleja la posibilidad de que haya más conversiones, agravándose así en buena medida la ya precaria labor de la Iglesia cristiana en estas latitudes. Según se constata en estos presidios norteafricanos, fueron frecuentes los casos de mujeres y hombres musulmanes que siendo comprados por judíos realizaron con prontitud su conversión a la fe cristiana, con el objetivo de alcanzar la libertad y con el empeño del propio esclavo, en vez de ser el resultado de una adecuada labor evangelizadora por parte de sus dueños judíos. Así le ocurre en Orán a Francisco, «esclavo de ayen cansino, judio, que de su voluntad se bino a bolber christiano» ${ }^{31}$ o a Antonio de Baeza, musulmán esclavo de una mujer judía que, «alumbrado del espiritu santo venia ante el dicho vicario a tomarse cristiano", siendo recluido en la iglesia de Santo Domingo de Orán para recibir una adecuada instrucción previa a su bautismo. La participación de su dueña para lograr la conversión del esclavo no aparece expresada en ningún momento. En realidad, ella no quiere quedarse sin esclavo, y Antonio lo único que busca es la libertad para poder salir de Orán y volver a vivir entre sus parientes musulmanes practicando su fe primera ${ }^{32}$.

Sobre la tarea catequizadora de la Iglesia cristiana respecto a los judíos que viven en algunos de los presidios cristianos del norte de África, ésta parte de los mismos presupuestos que la realizada con respecto a los musulmanes y, obviamente, padece sus mismas carencias. El vicario de Orán, Cristóbal de Villafañe, escribe en 1613, cómo es obligación de los tres conventos presentes en Orán -franciscanos, dominicos y mercedarios- el «enviar sus relixiones hombres doctos que enseñasen y predicassen nuestra santa fee assi a los christianos como a los moros y judios» ${ }^{33}$, mientras que la realidad es que estas personas que están al frente de la labor catequizadora de la Iglesia cristiana en esta tierra de infieles, «son muy honrradas y relixiosas (pero) no tienen la sufiçiençia y letras neçesarias para ello ni para enseñar ni responder a los judios que aqui viven y bienen de fuera los quales ossadamente dizen de su ley sin que se les de la satisfaçion que podrian hombres doctos y berssados en la sagrada scriptura». En la práctica, si corto es el número de musulmanes que abandonan la fe de Alá para practicar la de Cristo, aún menor es el de judíos que renuncian a la ley de Moisés. Pero es que la situación de este grupo confesional en los presidios cristianos en los que sí son admitidos es bien diferente a la de los musulmanes. En Orán, por ejemplo, los judíos viven manteniendo sus

\footnotetext{
31 ADT. Libro de Bautismos $\mathrm{n}^{\circ} 3$, fol. 225 v. $/ 31$ julio 1611.

32 AHN. Inq. Leg. 2022 / 39, fols. 28 v.- 35 r. / Afio 1624. Relación de causas presentadas ante el Santo Oficio de Murcia.

33 AGS. GA. Leg. 785, s.f. / 20 enero 1613. Carta del vicario Cristóbal de Villafaffe de Solís.
} 
creencias dentro de la ciudad, poseen su propio barrio y, aún es más, su propia sinagoga, donde realizan los ritos y ceremonias privativas de su fe. Para ellos, la circulación por estas plazas es libre, no acuden a ellas para pedir la conversión, ni son esclavos al servicio de ningún dueño cristiano. Por este motivo, es la Iglesia cristiana la que tiene que acercarse a ellos si quiere llevarles el evangelio de Cristo, y vista la escasez de clérigos y su inadecuada preparación es fácil comprender la causa de un número tan corto de conversiones entre los judíos habitantes del doble presidio. En algún momento es posible oir la voz de la propia Iglesia de Orán denunciando su exigua capacidad para reforzar esta labor evangelizadora frente al núcleo judío. Es entonces cuando se reconoce su responsabilidad a la hora de dar el primer paso para conseguir que los judíos abracen la fe cristiana. Mas para ello es imprescindible que las órdenes religiosas reciban un importante incremento en el número de clérigos que las forman y, sobre todo, que la preparación de los que acuden sea de una mayor cualificacion, para poder hacet frente a una tarea catequizadora en la que hay que ser mucho más convincente que con respecto a los musulmanes, pues, en el caso de estos últimos, ellos mismos son los que empiezan abriendo sus corazones a la nueva fe, lo que no ocurre respecto a los judíos ${ }^{34}$. Sin embargo, el paso del tiempo parece demostrar que éstas no son sino denuncias aisladas, a las que apenas se atiende.

En definitiva, y a modo de conclusión, la puesta en práctica de la cruzada pacífica contra el Islam se alejó en gran medida de los presupuestos teóricos bajo los cuales fue ideada. Esto se debió a que las valoraciones previas no fueron del todo correctas, sino que pecaron de una evidente desviación -por elevación - del punto de mira, al considerarse la empresa catequizadora del musulmán berberisco como algo sencillo y de fácil consecución una vez realizada la conquista cristiana de algunos enclaves del Magreb. Como consecuencia de este «error de cálculo» previo, nos encontramos con la presencia en las plazas cristianas del norte de África de unos eclasiásticos escasos en número y poco preparados para la labor que deberían realizar, lo que parece estar en escasa consonancia con la existencia de un proyecto definido y bien trazado en relación con la expansión de la fe cristiana en Berbería. En este sentido, la tarea evangelizadora desarrollada por la Iglesia cristiana en tierras del otro lado del Estrecho se muestra próxima a la realizada en la propia Península en relación con la conversión de los moriscos. Si en el caso de los moriscos, durante la primera mitad del siglo XVI «muy pocas medidas se tomaron para enseñar o imponer el cristianismo, por lo cual continuaron firmemente apega-

34 AGS. GA. Leg. 785, s.f. / 20 enero 1613. Carta del vicario Cristóbal de Villafañe de Solís. 
dos a sus viejas costumbres y prácticas religiosas» ${ }^{35}$, con respecto a los musulmanes de Berbería, también se observa cómo los esfuerzos realizados para su conversión al cristianismo, aunque existieron, no fueron todo lo constantes e intensos que debian haberlo sido para alcanzar los resultados esperados por la Iglesia. Teniendo en cuenta este contexto, resulta sencillo comprender la causa de que esta cruzada pacífica contra el Islam se tradujera en un escaso número de conversiones al cristianismo, exceptuando situaciones muy concretas, como son para los musulmanes las épocas de malas cosechas en Berbería. Precisamente por circunstancias de este tenor, las conversiones no solamente fueron escasas sino muy débiles, de tal forma que con más frecuencia de la deseada para la Iglesia cristiana los recién convertidos volvían en poco tiempo a recuperar su antigua fe musulmana. Incluso de entre los que habian sido enviados a España para su catequización y bautismo, llegado el momento, no eran pocos los que no dudaban en salit de España con dirección a Berbería para volver a abrazar el Islam.

Sin embargo, no sólo hay que culpar a la Iglesia cristiana de la precariedad con la que llevó a cabo su misión evangelizadora respecto al infiel en tierras del Magreb. La penuria que se vive en las plazas españolas allende el Estrecho provoca la aparición de un contexto plenamente inadecuado para la correcta acogida y el trato oportuno hacia estos musulmanes que, siendo esclavos o libres, deseaban acercarse al cristianismo. Hostigados por el gran aislamiento en el que quedan tras la conquista y sin poder recibir de España el dinero, alimentos, ropa y otros enseres necesarios para la subsistencia de su población, estrechez de la que también participan las órdenes religiosas allí presentes, estos presidios acaban siendo enclaves poco favorables para lograr convencer al musulmán de la falsedad de su religión y de la verdad del cristianismo:

"que aya en ellas algun amparo y personas fieles señaladas, para que acoxan y animen, a los que aviendo sido infieles, Moros, Turcos y judios, y alli se vienen a convertir a nuestra Santa Fe Catolica, porque es notable lastima y poca caridad verles passar alli hambres y desnudez, con otras miserias, sin que apenas haya quien les recoja, ni de un jarro de agua en el tiempo que alli andan con titulo de Catecumenos, ni despues de bautizados, lo qual causa quebrantar las almas y animos a los demas infieles que estan a la mira, para la misma conversion y bautismo, que si en esto huviesse algun particular cuydado, orden y caridad, muchos mas se convertirian» ${ }^{36}$.

35 M. J. RodRígueZ-SALGADO, Un Imperio en transición. Carlos V, Felipe II y su mundo. Barcelona, Crítica, 1992, p. 392.

36 D. SUÁREZ MONTAÑÉs, Avisos importantes para la Magestad del Rey Nuestro Señor..., fol. $60 \mathrm{v}$.

Hispania, del Mediterráneo al Atlántico 